\title{
Non-convexity and stress-path dependency of unsaturated soil models
}

\author{
Daichao Sheng • Dorival M. Pedroso • Andrew J. Abbo
}

Published online: 22 April 2008

(C) Springer-Verlag 2008

\section{Erratum to: Comput Mech}

DOI 10.1007/s00466-008-0268-0

The original version of this article unfortunately contained a mistake. The presentation of Fig. 7 was incorrect. The corrected figure is given below.

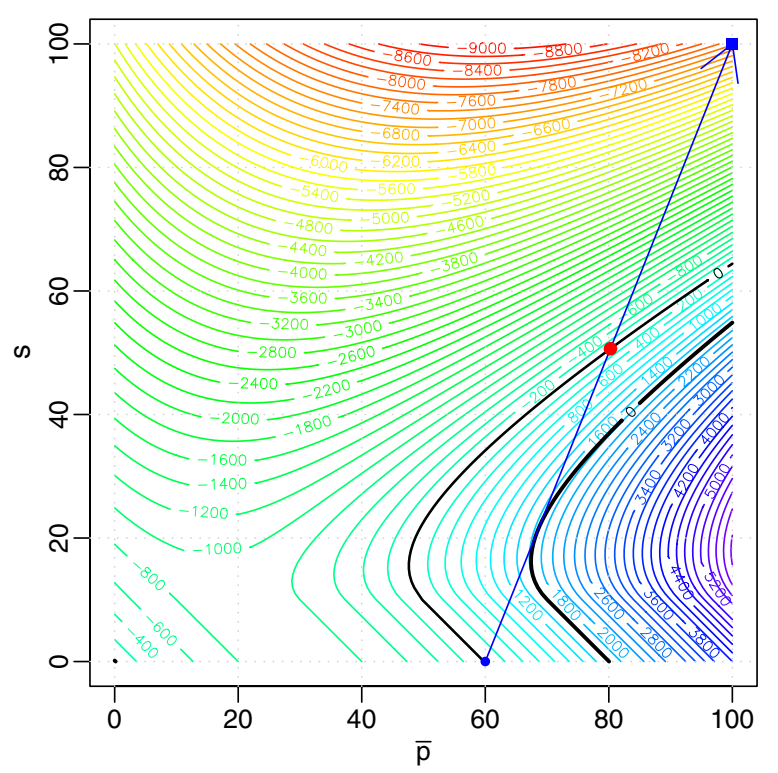

Fig. 7 Yield surface of SFG model and a stress-suction path with increasing suction. The initial state is inside the initial yield surface. After the first intersection, hardening takes place and the yield surface advances to the new position as shown

The online version of the original article can be found under doi:10.1007/s00466-008-0268-0.

D. Sheng $(\varangle) \cdot$ D. M. Pedroso · A. J. Abbo

Centre for Geotechnical and Material Modelling,

University of New Castle, New Castle, NSW 2308, Australia

e-mail: daichao.sheng@newcastle.edu.au 